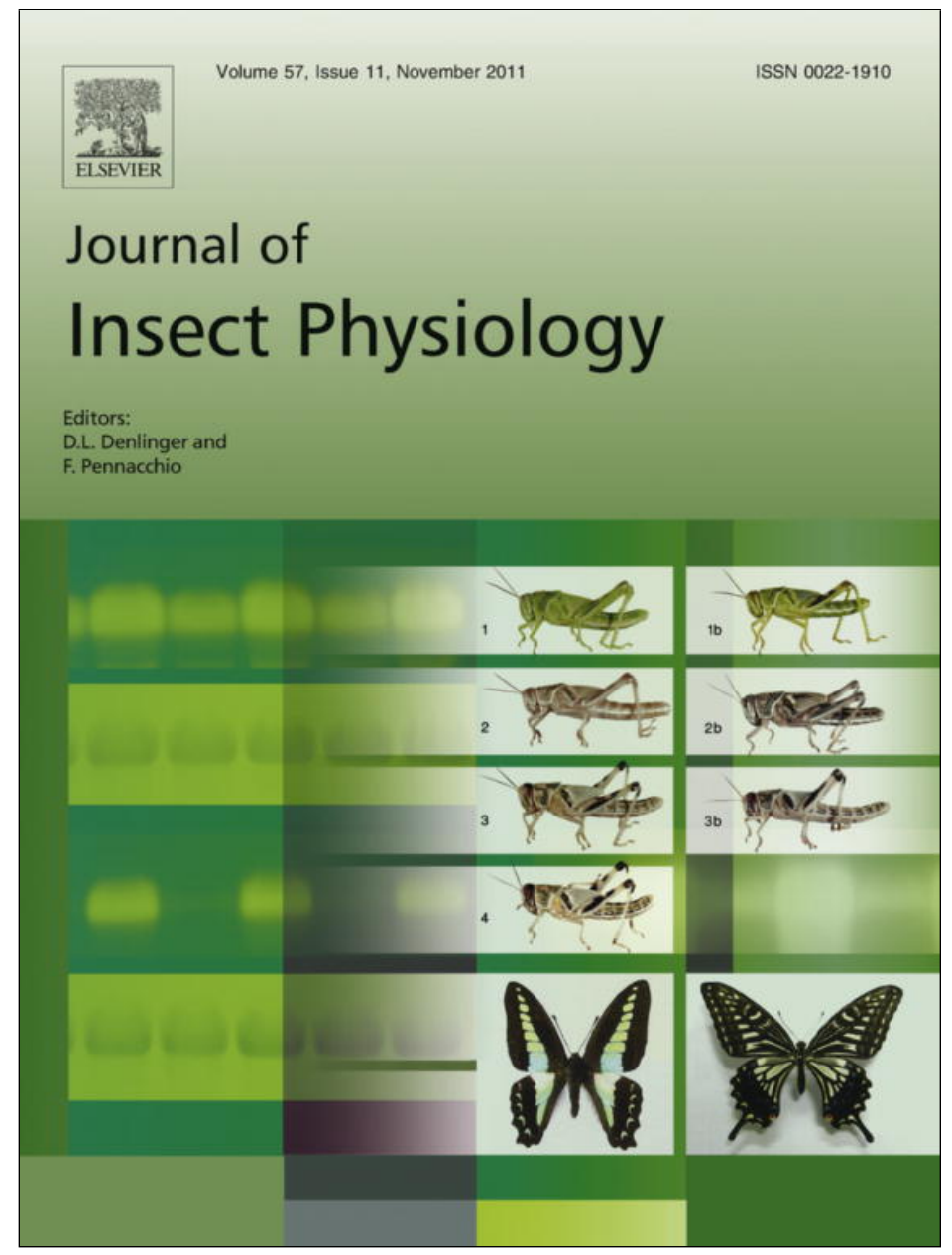

This article appeared in a journal published by Elsevier. The attached copy is furnished to the author for internal non-commercial research and education use, including for instruction at the authors institution and sharing with colleagues.

Other uses, including reproduction and distribution, or selling or licensing copies, or posting to personal, institutional or third party websites are prohibited.

In most cases authors are permitted to post their version of the article (e.g. in Word or Tex form) to their personal website or institutional repository. Authors requiring further information regarding Elsevier's archiving and manuscript policies are encouraged to visit:

http://www.elsevier.com/copyright 


\title{
Longevity of multiple species of tephritid (Diptera) fruit fly parasitoids (Hymenoptera: Braconidae: Opiinae) provided exotic and sympatric-fruit based diets
}

\author{
Charles Stuhl $^{\mathrm{a}, \mathrm{b}, *}$, Lizette Cicero $^{\mathrm{e}}$, John Sivinski ${ }^{\mathrm{b}}$, Peter Teal ${ }^{\mathrm{b}}$, Stephen Lapointe ${ }^{\mathrm{c}}$, \\ Beatriz Jordão Paranhos ${ }^{\mathrm{d}}$, Martín Aluja ${ }^{\mathrm{e}}$ \\ ${ }^{a}$ Entomology and Nematology Department, University of Florida, Gainesville, FL, USA \\ ${ }^{\mathrm{b}}$ USDA-ARS, Center for Medical, Agricultural and Veterinary Entomology, Gainesville, FL, USA \\ ${ }^{\mathrm{C}}$ USDA-ARS, Horticultural Research Laboratory, Ft. Pierce, FL, USA \\ ${ }^{\mathrm{d}}$ Laboratory of Entomology, Embrapa Semiarid, BR 248, km 152, C.P. 23, 56.302-970 Petrolina-PE, Brazil \\ ${ }^{\mathrm{e}}$ Instituto de Ecologia, A.C., Apartado Postal 63, 91000 Xalapa, Veracruz, Mexico
}

\section{A R T I C L E I N F O}

\section{Article history:}

Received 4 March 2011

Received in revised form 14 July 2011

Accepted 20 July 2011

Available online 3 August 2011

\section{Keywords:}

Utetes anastrephae

Doryctobracon areolatus

Doryctobracon crawfordi

Diachasmimorpha longicaudata

Opius hirtus

Psidium guajava

\begin{abstract}
A B S T R A C T
While adult parasitic Hymenoptera in general feed on floral and extrafloral nectars, hemipteran-honeydews and fluids from punctured hosts, Diachasmimorpha longicaudata (Ashmead), an Old World opiine braconid introduced to tropical/subtropical America for the biological control of Anastrepha spp. (Tephritidae), can survive on fruit juices as they seep from injured fruit. An ability to exploit fruit juice would allow such a parasitoid to efficiently forage for hosts and food sources simultaneously. Two New World opiines, Doryctobracon areolatus (Szepligeti) and Utetes anastrephae (Viereck), are also prominent Anastrepha parasitoids and are roughly sympatric. All three species were provided with: (1) pulp and juice diets derived from a highly domesticated Old World fruit (orange, Citrus sinensis L.) that is only recently sympatric with the Mexican flies and parasitoids and so offered little opportunity for the evolution of feeding-adaptations and (2) a less-domesticated New World fruit (guava, Psidium guajava L.), sympatric over evolutionary time with $D$. areolatus and $U$. anastrephae. Both sexes of $D$. longicaudata died when provided guava pulp or juice at a rate similar to a water-only control. D. areolatus and $U$. anastrephae, presumably adapted to the nutrient/chemical constituents of guava, also died at a similar rate. Survival of all three species on orange pulp and juice was greater than on water, and often equaled that obtained on a honey and water solution. In confirmatory experiments in Mexico, D. areolatus and $U$. anastrephae, as well as other tephritid parasitoids Doryctobracon crawfordi (Viereck) and Opius hirtus (Fisher), all died at a significantly higher rates when provided guava in comparison to a honey and water diet. Such a result is likely due to guavas being repellent, innutritious or toxic. D. longicaudata clearly consumed guava juice tagged with a colored dye. Dilutions of orange and guava juice resulted in shorter lifespans than dilutions of orange juice and water demonstrating that there while diluted orange juice provided nutrition the addition of guava created toxicity. Given the differences in fruit-food quality, adult opiine food sources would not be obtainable at all oviposition sites and in the case of guava, more additional sites and foraging for food than previously postulated may be required.
\end{abstract}

Published by Elsevier Ltd.

\section{Introduction}

Adult hymenopteran parasitoids consume a variety of foods including flower nectar (Jervis et al., 1996), extrafloral nectar (Koptur, 1989), host fluids (Jervis and Kidd, 1999) and hemipteran honeydew (Wäckers, 1999, 2001). Fruit or fruit juices, while an

\footnotetext{
* Corresponding author at: USDA-ARS, Center for Medical, Agricultural and Veterinary Entomology, 1600 SW 23rd Dr., Gainesville, FL, USA. Tel.: +1 352374 5704; fax: +1 3523745781 .

E-mail address: charles.stuhl@ars.usda.gov (C. Stuhl).
}

obvious food source for a "fruit fly" parasitoid, are only rarely reported as feeding substrates. The tephritid-attacking opiine braconid Diachasmimorpha longicaudata (Ashmead) consumes juices seeping from injured citrus and other fruits (Sivinski et al., 2006) and a parasitoid of drosophilids, Asobara spp. (Braconidae) feeds on fermenting fruit (Eijs et al., 1998). Since adult tephritid fruit fly parasitoids occur in the same habitats as adult flies (Aluja and Birke, 1993), there may be widespread opportunities to exploit the same nutritional resources, particularly juice expelling from ovipositor-wounded or infested fruit. Since parasitoids incur costs and risks foraging for adult food separate from hosts (Bernstein 
and Jervis, 2008), a competitive advantage could accrue to individuals that concentrate their feeding and breeding within the same resource patches (Sivinski et al., 2006). However, fruit juices, just as other plant-produced substances, vary in nutritional quality and some contain compounds particularly detrimental to Hymenoptera, including toxic sugars (Barker, 1977).

Opiine braconids are typically the most abundant/diverse frugivorous-tephritid parasitoids (López et al., 1999; Sivinski et al., 2000), and can be mass-reared and inundatively released for area-wide control (Sivinski et al., 1996; Montoya et al., 2000). We compared the longevity of three opiine species, all larvalprepupal koinobionts that attack Anastrepha spp. fruit flies in Mexico and throughout much of the neotropics, when provided with the pulp and juice of two different fruits, Psidium guajava L. (guava; Myrtaceae) and Citrus sinensis L. (orange; Rutaceae). The parasitoids Doryctobracon areolatus (Szepligeti) and Utetes anastrephae (Viereck) are Latin American natives and share an evolutionary history with guava (Wharton and Marsh, 1978; Morton, 1987) but not with the exotic and highly domesticated orange. D. longicaudato was originally collected in the Indo-Philippine region attacking Bactrocera spp. and has only been established in the native range of guava over the last half century (Ovruski et al., 2000). Unlike $D$. areolatus and $U$. anastrephae, whose host-searches are concentrated in fruit tree canopies where fruit is less likely to be damaged (Sivinski et al., 1997), D. longicaudata forages extensively in fallen fruit (Purcell et al., 1994) and so might have more immediate access to injured and oozing fruit.

Given the differences in parasitoid foraging and the possibility that fruits might differ both nutritionally and in terms of unfavorable compounds we hypothesized that: (1) D. areolatus and $U$. anastrephae would find the historically sympatric guava a superior food to orange; (2) D. longicaudata would survive equally well on either fruit, or possibly longer on the more roughly sympatric orange; (3) D. longicaudata would be better adapted to a diet of fruit juice because of its ground-based foraging habits and would live longer on a fruit diet relative to a honey and water control than would D. areolatus or U. anastrephae; and (4) in confirmatory experiments in Mexico, D. areolatus and $U$. anastrephae, as well as the native tephritid parasitoids Doryctobracon crawfordi (Viereck) and Opius hirtus (Fisher) would survive at least as well on a guava diet as on a honey + water control. Early results suggested the presence of a toxic component in guava and we subsequently searched for toxic sugars in the fruits. This in turn led to the exposure of $D$. longicaudata to diets containing a candidate compound.

Ultimately, studies of foods that enhance adult parasitoid survival in the field could improve the diets of parasitoids massreared for augmentative releases and help direct natural enemy introduction and conservation (Sivinski et al., 2006). In addition, volatiles from these natural foods may be attractive and could be incorporated into traps that would help monitor the survival and dispersal of released parasitoids.

\section{Materials and methods}

\subsection{Source of USA parasitoids}

D. longicaudata, D. areolatus and U. anastrephae, were obtained from colonies the USDA-ARS, Center for Medical, Agricultural and Veterinary Entomology (USDA-ARS, CMAVE), Gainesville, Florida, USA. D. longicaudata had been in colony for approximately 10 years, and $D$. areolatus and $U$. anastrephae for approximately 4 years. All parasitoids were reared on larvae of the Caribbean fruit fly, Anastrepha suspensa (Lowe) that developed in an artificial diet (FDACS, 1995) obtained from the Florida Department of Agriculture and Consumer Services Division of Plant Industries,
Gainesville, Florida, USA. Insects were reared in a temperature controlled chamber at $23 \pm 5^{\circ} \mathrm{C}, 60 \% \mathrm{RH}$, and photoperiod of 12:12 (L:D) h. Breeding colony adults were fed a diet of $10 \%$ honey/sugar solution.

\subsection{Survival on alternative fruit-based diets}

Parasitoids were provided with a food source and/or water within $24 \mathrm{~h}$ of eclosion. Ripe guava was collected from a small orchard organically grown at USDA-ARS, CMAVE, Gainesville, Florida, USA. Fruits were cut into quarters and a single quarter ( $\sim 40 \mathrm{~g}$ ) was presented as a source of moist pulp. Guava juice was extracted from peeled ripe fruit by pressing the pulp through a mesh to remove the seeds. The pulp and an equal amount of water were blended together. Juice was collected by filtering the blend through cloth to separate the solids from the juice. Orange pulp was prepared from organic fruit purchased from a local market then peeled, sectioned ( $\sim 60 \mathrm{~g})$ and sliced crosswise to expose pulp. Juice was manually extracted.

Each repetition consisted of three $20 \times 20 \times 20 \mathrm{~cm}$ mesh and Plexiglas $^{\circledR}{ }^{\circledR}$ cages containing 25 male and 25 female parasitoids. In one cage the insects were presented with either guava or orange juice or pulp (see below) and a $118 \mathrm{ml}$ water cup with a protruding cotton wick. Juices were presented in saturated cotton balls inside a $60 \mathrm{ml}$ cup. Another cage contained a $118 \mathrm{ml}$ cup of water and $\sim 1 \mathrm{ml}$ of honey (pure unfiltered, uncooked) smeared on $5.5 \mathrm{~cm}$ dia. filter paper and placed in a $9 \mathrm{~cm}$ dia. Petri dish. The third cage contained only a $118 \mathrm{ml}$ cup of water. Food sources were replaced daily to ensure freshness. Each treatment was replicated 5 times. Because insects in one treatment cage were not independent from one another, the survival is quantified as the total lifetimes of all insects in one treatment cage. Analyses of variance (ANOVA) followed by a Dunnett's test were used to determine differences among the total lifetimes for all treatments for both sexes of each species.

\subsection{Survival on guava relative to honey (Mexico)}

To confirm the generality of Florida results, $D$. longicaudata and $U$. anastrephae from colonies at the Instituto de Ecología, A. C. in Xalapa, Veracruz, México were exposed to guava, as were additional non-native opiine fruit fly parasitoids (Doryctobracon crawfordi [Viereck] and O. hirtus [Fischer]). All were reared on larvae of the Mexican fruit fly, Anastrepha ludens (Lowe) that had developed in an artificial diet (FDACS, 1995). A single newly emerged female parasitoid was placed in a $2 \mathrm{~cm}$ Petri dish that contained water in a $5 \mathrm{ml}$ vial with a cotton wick and one of three diet treatments: (1) Honey ad libitum, (2) honey every second day and (3) organic guava pulp/juice (purchased from a local market). Guava was replaced daily to guarantee freshness. Different cohorts of each parasitoid ( $\sim 15$ females) species/food treatment were examined at $3,6,9,12$, and 15 days and the proportions that had survived that length of time were calculated. Survival rates were compared on a pair wise basis using repeated regressions in which time and diet served as independent variables (Zar, 1974). Proportional data were $\log$-arsine transformed prior to analysis.

\subsection{Survival on mixed guava/orange juice compared to diluted orange juice}

Preliminary results found significantly shorter lifespans in parasitoids fed guava. To determine if guava was innutritious or harmful, $D$. longicaudata were provided with various orange and/or guava diets within $24 \mathrm{~h}$ of emergence. The treatments consisted of guava juice; orange juice; 1:1 mixture of guava/orange juice; $1: 1$ orange juice/water dilution and a water control. This allowed 
Diachasmimorpha longicaudata males
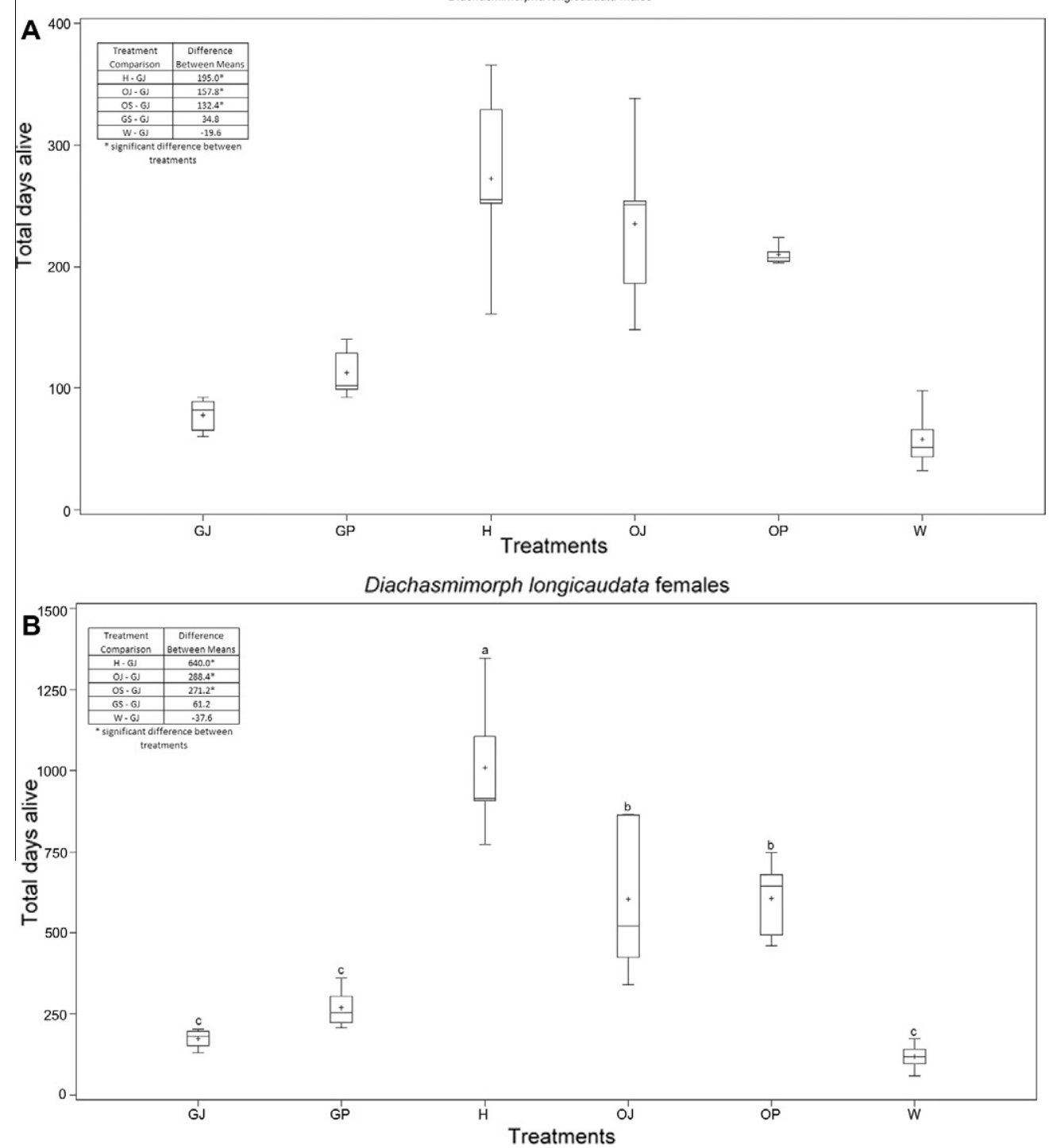

Doryctobracon areolatus males

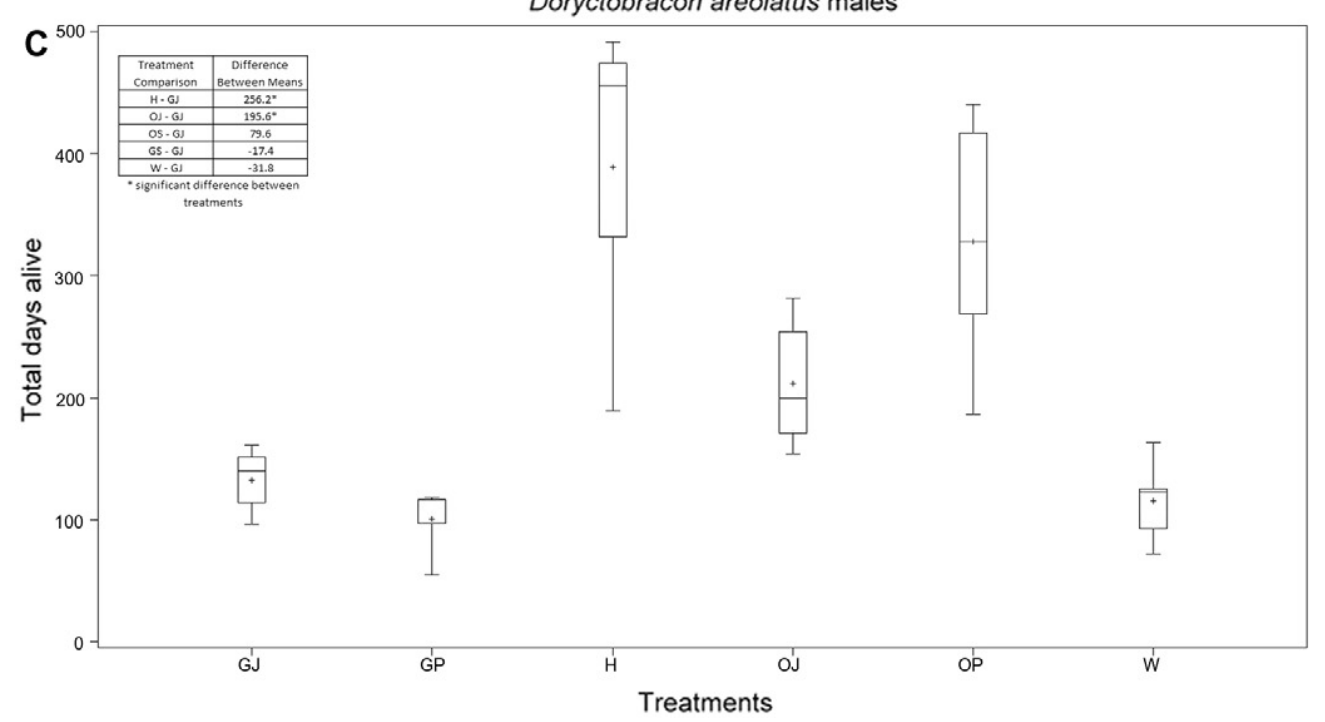

Fig. 1. Survival of Diachasmimorpha longicaudata (a and b), Doryctobracon areolatus (c and d) and Utetes anastrephae (e and $\mathrm{f}$ ) on various diets (GJ = guava [Psidium guajava] juice, $\mathrm{GP}=$ guava pulp, $\mathrm{H}=$ honey, $\mathrm{OJ}=$ orange [Citrus sinensis] juice, $\mathrm{OP}=$ orange pulp, $\mathrm{W}=$ water). The $Y$ axis measures the sum of days lived by all 25 individuals (i.e. $100 /$ 25 = 4 days); the $\mathrm{X}$ axis corresponds to the treatments. The box represents the middle $50 \%$ of the data. The upper boundary of the box locates the 75 th percentile of the data set, while the lower boundary indicates the 25 th percentile. The mean is represented by a plus sign (+) in the center of each box. The line in the box represents the median value. The whiskers represent the minimum and maximum values of the data set. An $(*)$ denotes a significant difference between the paired treatments. 


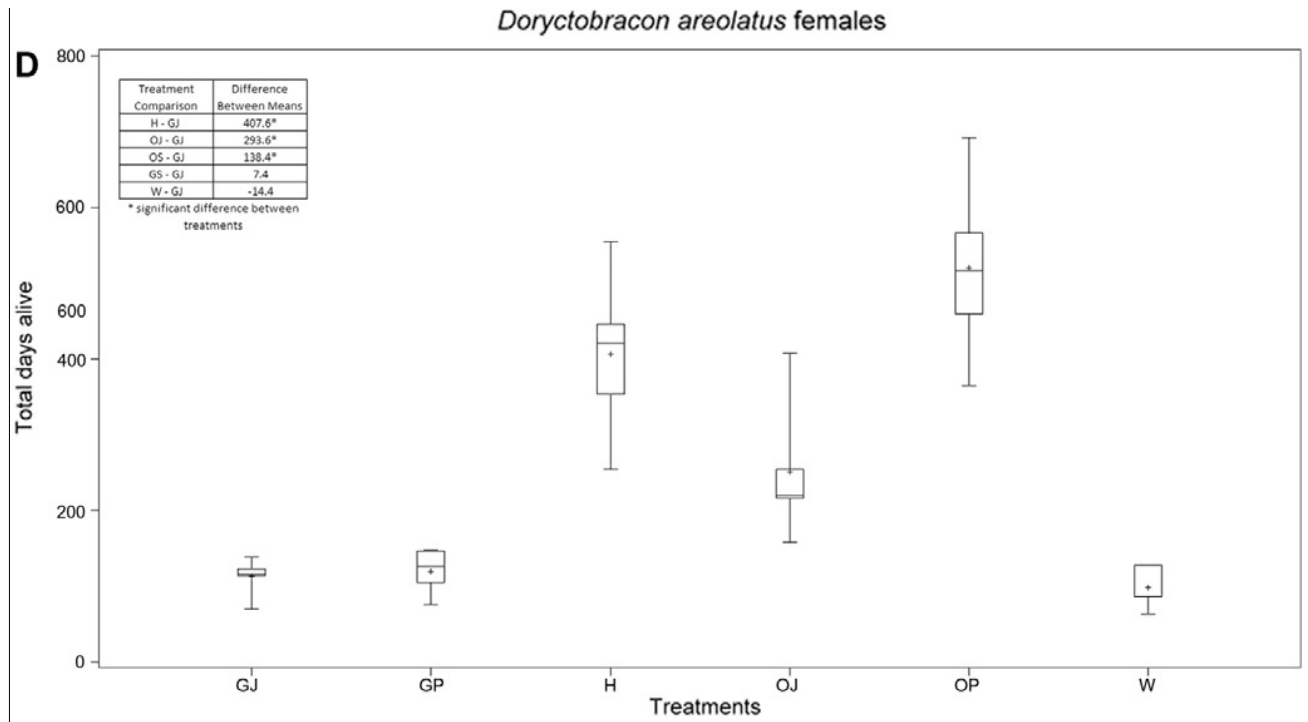

Utetes anastreaphae males
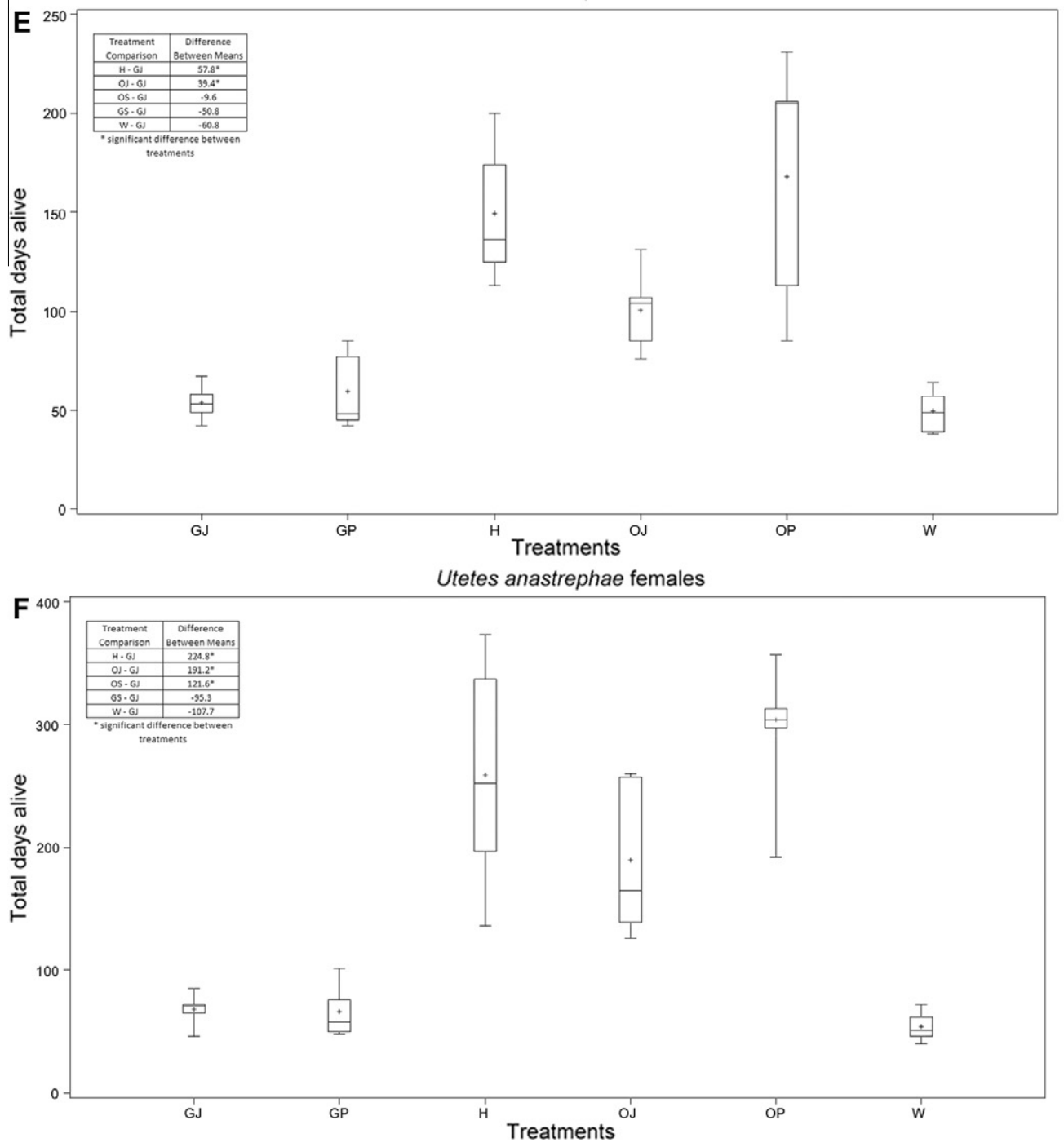

Fig. 1 (continued)

us to determine if any decrease in longevity occurred due to substance present in guava juice (guava juice + orange juice $=$ guava juice alone) or innutritious (guava juice + orange juice $>$ guava juice alone; orange juice dilution = guava juice + orange juice). For each treatment, 10 male and 10 female $D$. longicaudata were individually placed in $470 \mathrm{ml}$ clear polypropylene containers. A 


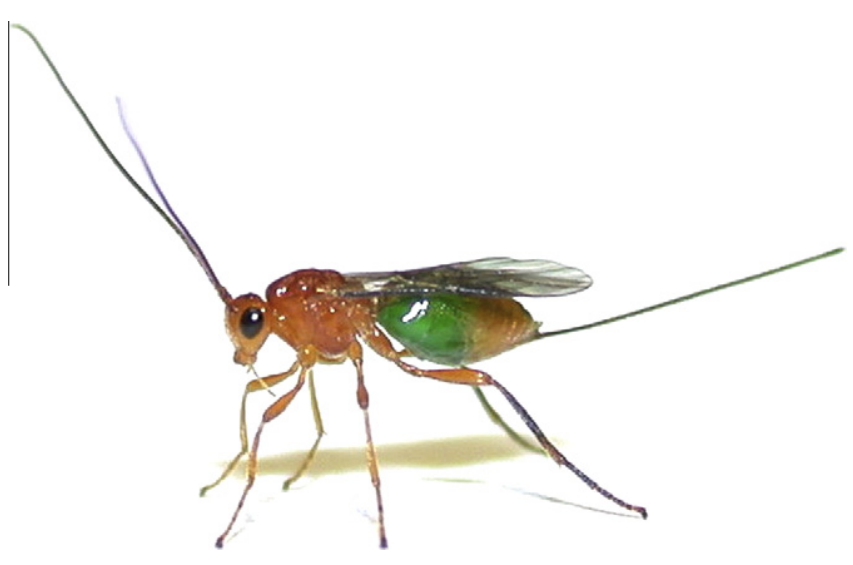

Fig. 2. Visual confirmation that a female Diachasmimorpha longicaudata has fed on guava juice mixed with $2 \mu \mathrm{l} / \mathrm{ml}$ green food dye.

$7.5 \mathrm{~cm}$ hole was placed in the center of the lid and replaced with organdy cloth. A $12 \mathrm{~mm}$ dia. hole was placed in the side of the container to introduce the insect and blocked with a foam plug. Two $10 \mathrm{~mm}$ dia. holes were placed in the bottom of the container to allow cotton wicks to protrude into the cup (one for treatment, one for water). Treatment solutions were held below in a $30 \mathrm{ml}$

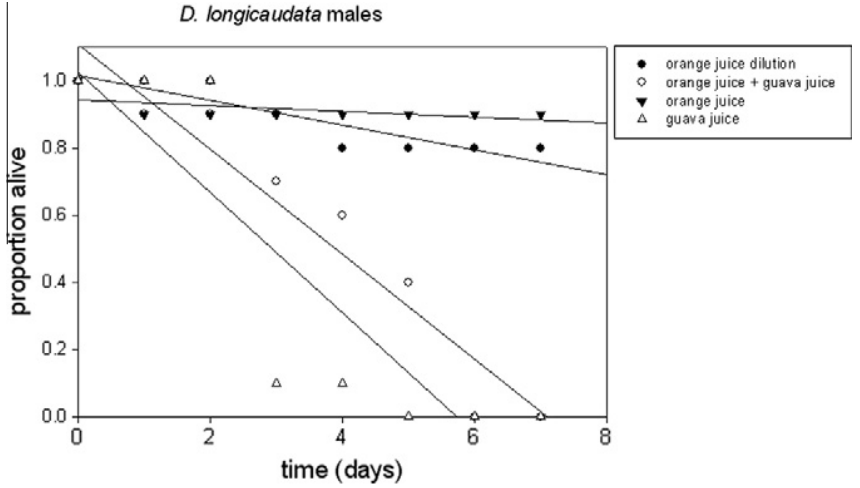

Fig. 4a. Proportion of male Diachasmimorpha longicaudata surviving on solutions of orange juice, 1:1 dilution of orange juice and water, guava juice, 1:1 mixture of orange juice and guava juice and a water control over time.

cup. The bioassay ended when all of the insects fed the guava juice + orange juice had died. Separation of means was accomplished by ANOVA followed by Waller's test (SAS Institute, 2002). To ensure the treatments were ingested by the insects, in a separate test, juices were dyed using $2 \mu \mathrm{l} / \mathrm{ml}$ of green food dye (McCormick \& Co., Inc., Hunt valley, MD). This enabled us to visually confirm the treatment within the gut of the insect.
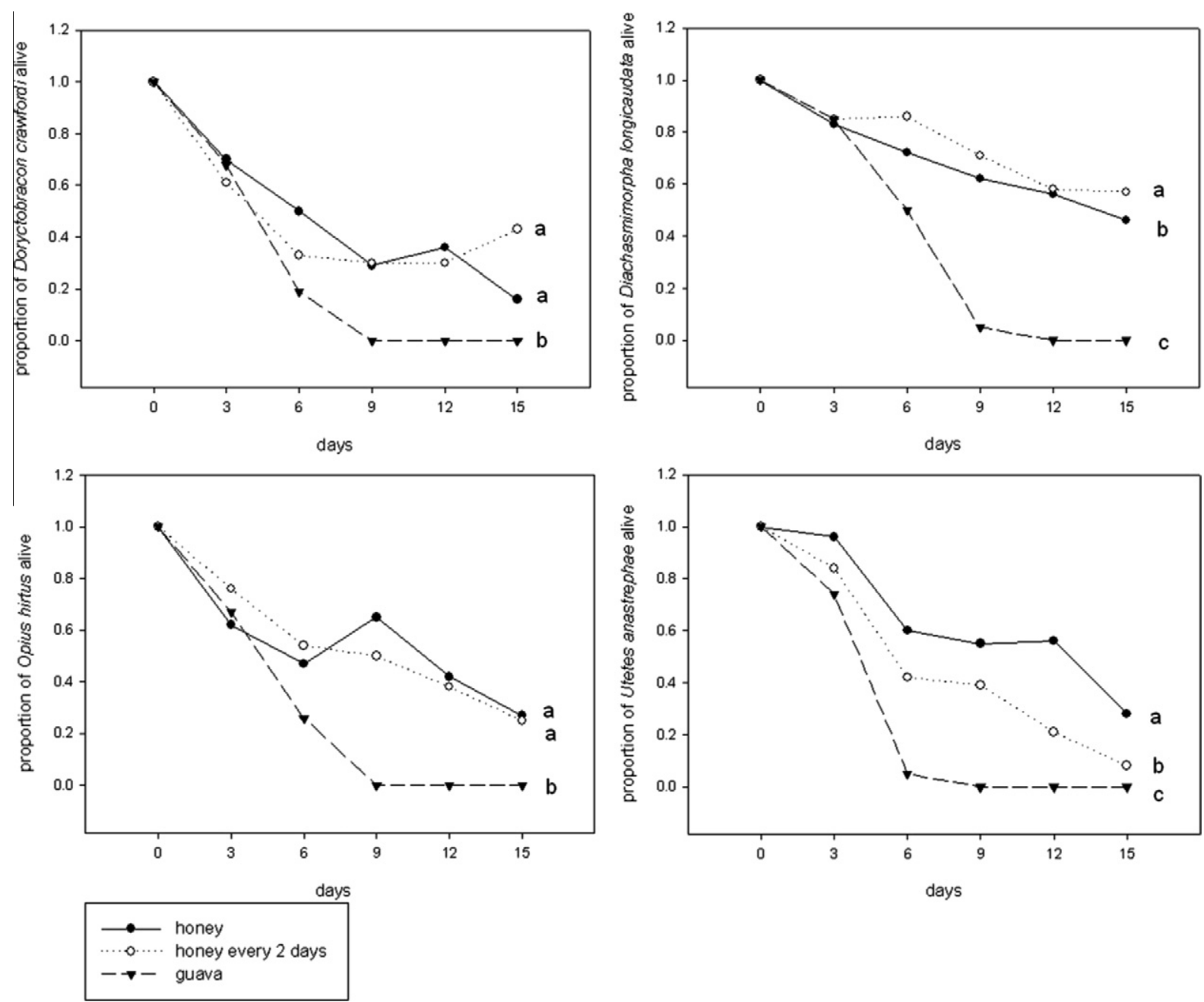

Fig. 3. The proportions of Doryctobracon areolatus, Diachasmimorpha longicaudata, Opius hirtus and Utetes anastrephae cohorts maintained on guava [Psidium guajava], honey every day or honey every other day that was alive after various lengths of time. Regressions sharing letters are not significantly different. 


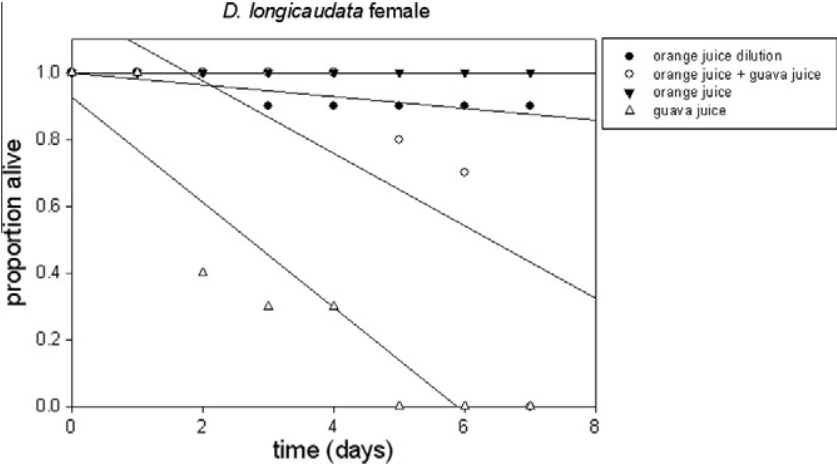

Fig. 4b. Proportions of female Diachasmimorpha longicaudata surviving solutions of orange juice, 1:1 dilution of orange juice and water, guava juice, 1:1 mixture of orange juice and guava juice and a water control over time.

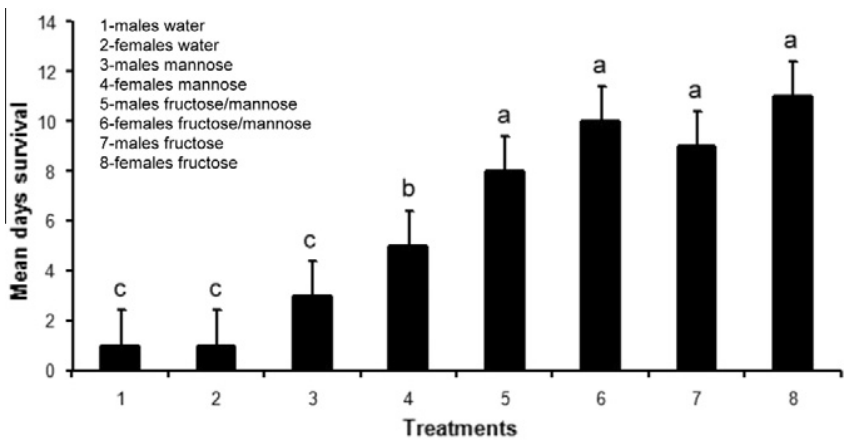

Fig. 5. Mean days of survival for male and female Diachasmimorpha longicaudat survival on aqueous $5 \%$ solutions of fructose, mannose and fructose and mannose.

\subsection{Identification of sugar constituents and survival on a potentially} toxic sugar

The toxicity of guava fruit and juice (see Results) prompted us to investigate potential toxins. Certain sugars, arabinose, mannose, raffinose, lactose and rhamnose, can be nutritious to mammals but poisonous to honey bees (Apis mellifera L.) and Cotesia glomerata (Barker, 1977; Wäckers, 2001). A commercial carbohydrate analysis of guava fruit (EMSL Analytical, Inc., Westmont, NJ), identified sugars at concentrations greater than $0.022 \mathrm{mg} / \mathrm{g}$. Only fructose $37 \mathrm{mg} / \mathrm{g}$, glucose $20 \mathrm{mg} / \mathrm{g}$ and sucrose $38 \mathrm{mg} / \mathrm{g}$ were identified. Orange juice contains: fructose $18.4 \mathrm{~g} / \mathrm{l}$, glucose $15.3 \mathrm{~g} / \mathrm{l}$ and sucrose $37.8 \mathrm{~g} / \mathrm{l}$ (Muntean, 2010), although higher fructose levels, $20-38 \mathrm{mg} / \mathrm{ml}$ (Villamiel et al., 1998 and citations) have been reported. Thus, fructose, a known opiine nutrient and the positive control in the experiments described below, occurs in roughly similar levels in orange.

Since toxic sugars might have been present at undetectable levels we performed a more sensitive analysis, Gas Chromatography-Mass Spectrometry (GC-MS), of guava and orange pulp. Mannose has been previously detected in guava but not in the peel and membranes from orange (Grohmann et al., 1995).

GC-MS is only useful for monosaccharides, so large oligo- or polysaccharides must first be hydrolyzed to their component monosaccharides through an acylation technique (Price, 2004). Fruit samples were dried using a food dehydrator (Mr. Coffee FD53196) then pulverized to a fine powder. A $0.50 \mathrm{mg}$ sample was placed in a reaction vial with $100 \mu$ of aqueous 2 M trifluoroacetic acid (TFA) and heated in a water bath at $110^{\circ} \mathrm{C}$ for $30 \mathrm{~min}$. The sugars in solution were then evaporated to dryness. About $0.5 \mathrm{ml}$ of hydroxylamine hydrochloride in pyridine $(33 \mathrm{mg} / \mathrm{ml})$ was added and reacted in a water bath at $60^{\circ} \mathrm{C}$ for $30 \mathrm{~min}$. The sample was cooled, and without evaporating, $200 \mu \mathrm{l}$ of acetic anhydride was added and heated in a water bath at $60{ }^{\circ} \mathrm{C}$ for $30 \mathrm{~min}$ thus completing the peracetylation. The reaction was quenched after $30 \mathrm{~min}$ by the addition of $3 \mathrm{ml}$ of mili-Q water. The sugars were extracted by partitioning with $2 \mathrm{ml}$ ethyl acetate. The upper organic layer was used directly for GC/MS analysis. A $1 \mu \mathrm{l}$ injection was equivalent to $1 \mu \mathrm{g}$ of the underivatized sugar. Mass spectra were recorded over the range $m / z 50-550$ in positive ion mode. It was important to have the low range cutoff set at 50 otherwise the spectra are dominated by an acetate ion at $m / z 43$.

\subsection{Mannose bioassay}

Assays described above found the potentially toxic sugar mannose in guava, but not in oranges (see results). Consequently we exposed $D$. longicaudata to mannose (Sigma-Aldrich) to examine its effect on parasitoid survival. The treatments consisted of a $5 \%$ mannose $+10 \%$ fructose solution, a $5 \%$ mannose solution and a water control. This allowed us to determine if any decrease in longevity in the presence of mannose was due to toxicity (mannose + fructose $=$ mannose alone) or innutrition (mannose + fructose $>$ man nose alone and mannose alone = water control). Sugar concentrations of $1 \mathrm{M}(1 \mathrm{M})$ have been shown to increase parasitoid longevity. A $10 \%$ fructose solution can maintain $D$. longicaudata for over 30 days (Stuhl unpublished data). For each treatment, five male and five $\sim 2$ day old female $D$. longicaudata were individually placed in $470 \mathrm{ml}$ clear polypropylene containers with a lid replaced with organdy cloth. A $10 \mathrm{~mm}$ diameter hole was placed in the bottom of the container to allow a saturated cotton wick containing the treatments to protrude into the cup. Ten individuals (five males and five females), for a total of five replications were performed. The bioassay ended when all of the insects died. Separation of means was accomplished by ANOVA followed by Waller-Duncan means separation test (SAS Institute, 2002).

\section{Results}

\subsection{Survival on alternative fruit-based diets}

Mean longevities of both sexes of all three species provided with the pulp and juice of guava were indistinguishable from those obtained on water alone (Fig. 1a-f), this in spite of its repeatedly observed ingestion (Fig. 2). When provided with orange juice, but not orange pulp, male $D$. areolatus and $U$. anastrephae life spans were statistically similar to those given guava juice. In both sexes of $D$. areolatus and $U$. anastrephae survival on orange pulp was greater than on juice, but in male and female $D$. longicaudata there was no difference between pulp and juice. In general, orange diets were superior to either water alone or guava diets and typically insects with orange diets lived as long as those with honey diet.

\subsection{Survival on guava compared to honey (Mexico)}

In all 4 species of parasitoids survival rates were lower on diets of guava than those fed either honey or honey every other day (Fig. 3). In D. longicaudata and $U$. anastrephae insects fed honey every day survived at a greater rate than those fed honey every other day.

\subsection{Survival on guava/orange juice mixtures relative to diluted orange juice}

Both male and female $D$. longicaudata fed with guava died at a greater rate than those fed with oranges. Survival on a 1:1 orange 
juice + guava juice mixture was no greater than that obtained on guava juice alone (Figs. $4 \mathrm{a}$ and $4 \mathrm{~b}$ ) and was less than a 1:1 mixture of orange juice and water.

\subsection{Identification of and survival on potentially toxic sugars}

GC-MS analysis of guava utilizing an acylation technique showed the presence of mannose in our samples. Mannose was not detected in orange. We did not quantify the amount, only verified its presence.

\subsection{Survival on solutions of mannose}

Mannose was not toxic at a level that exceeds its reported concentration in guava either in combination with fructose or alone (Fig. 5). In fact mannose alone was slightly nutritious as it extended life significantly beyond a water-alone diet.

\section{Discussion}

Carbohydrates and other nutrients are critical for the survival and continued fecundity of synovigenic parasitoids, and $D$. longicaudata shows an ability to acquire these from a variety of sources. One source, juices that seep from certain injured fruits, provides a high quality diet and minimizes the need to separately forage for oviposition sites and adult food (Sivinski et al., 2006). However, fruits, as well as flower nectars and other plant exudates vary in nutritional quality and some may contain detrimental compounds, including toxic sugars (Barker, 1977; Wäckers, 2001). Because of these potential problems with fruit-foods we hypothesized that the native Mexican opines, $D$. areolatus and $U$. anastrephae being sympatric with guava would be adapted to its use and find it particularly suitable. On the other hand, we proposed that the exotic D. longicaudata would not fare as well on guava but be the best able to exploit a fruit of Old World derivation, $C$. sinensis, or at least do as well on this highly modified fruit as the New World parasitoids. In addition, we postulated that another two Mexican species, $D$. crawfordi and $O$. hirtus would find guava nutritious and life-sustaining relative to a honey solution. Because of a host-foraging strategy that brings $D$. longicaudata into closer contact with fallen, overripe and damaged fruit than either D. areolatus or U. anastrephae we predicted that it might be better adapted to feed on fruit juices. If so, we expected $D$. longicaudata life spans on fruit-based diets to be the highest of the three species relative a honey solution. These suppositions were almost all incorrect.

Both sexes of $D$. longicaudata, from USA and Mexican-derived cultures died at similar rates when provided guava pulp or juice or a water-only control. In the USA $D$. areolatus and $U$. anastrephae, presumably adapted to the nutrient/chemical constituents of guava, also died at a rate similar to that of the water-control. Survival of all three species on orange pulp was greater than on water and longevity often equaled that obtained on a honey positive control. In Mexico, D. areolatus and U. anastrephae, as well as the tephritid parasitoids $D$. crawfordi and $O$. hirtus, died at significantly higher rates when provided guava in comparison to two feeding schedules of a honey diet.

This general $P$. guajava-induced mortality could be due to guavas being (1) unlocatable/repellent, (2) innutritious or (3) toxic (sensu lato). D. longicaudata clearly consumed guava juice tagged with a colored dye. Dilutions of orange and guava juice resulted in shorter lifespans than dilutions of orange juice and water demonstrating that while diluted orange juice provided nutrition the addition of guava created toxicity. Mannose, a sugar known to be toxic to some Hymenoptera (De la Fuente et al., 1986), occurred in guava but was not detected in citrus. However, it was slightly nutritious to female $D$. longicaudata, leaving the toxic compound(s) unidentified.

Given the differences in fruit-food quality, adult opiine food would not be obtainable at all oviposition sites and more foraging for food than previously postulated may be required (Sivinski et al., 2006). This would be a particular handicap for $D$. areolatus which is more likely than $U$. anastrephae to be recovered from hosts infesting guava (López et al., 1999; Sivinski et al., 2000; literature compilation obtainable from john.sivinski@ars.usda.gov). Psidium specialists, or near specialists, occur among Mexican endemic tephritid parasitoids outside of the Opiinae. The figitid Odontosema albinerve Kieffer (=Odontosema anastrephae, sensu Kieffer) is largely associated with guava and its congeners, as is to a lesser extent another figitid, Aganaspis pelleranoi. It remains to be seen if the compounds toxic to the braconid members of the parasitoid guild also effect specialist adult Figitidae.

It remains a mystery why multiple species of braconids, some sympatric with a host fruit and the flies that inhabit it over evolutionary time, have not evolved a tolerance to an abundant and convenient food source. Since the fruits tested were uninfested the harmful compound is not a host-product designed to discourage natural enemies. Neither is it obvious why guavas would produce a compound harmful to the parasitoids of larvae that might damage seeds or compromise the attractiveness of fruit to seed dispersers. Perhaps opiine mortality is simply a by-product of selection in some other context such as discouraging an unidentified seedpredator.

Several species of opiine braconid parasitoids of pest tephritids are mass-reared for augmentative release and are typically fed with honey or honey solutions (Sivinski et al., 1996; Wong and Ramadan, 1993). But little is known about their dietary requirements, and even less about potential food sources in the field. Since the sustained efficacy of a release might be impacted by the availability of adult food, it is important to determine the nutritional landscape parasitoids might encounter. It is now clear that guava is not an exploitable resource. Ultimately, examination of natural foods might suggest diet improvements that lead to longer lived, more fecund and healthier mass-reared parasitoids for more efficacious biological control.

\section{Acknowledgements}

We thank Tim Holler (USDA-APHIS [ret.]) for allowing us to remove insects from his parasitoid colonies; he helped with field collections and was instrumental in performing many of the experiments. Florida Department of Agriculture and Consumer Services (FDACS), Division of Plant Industry generously supplied Anastrepha suspensa larvae. M. Aluja acknowledges support from CONACyT through a Sabbatical Year Fellowship (Ref. 79449) and thanks Benno Graf and Jörg Samietz (Forschungsanstalt Agroscope Changins-Wädenswil ACW, Switzerland) for providing ideal conditions to work on this paper.

\section{References}

Aluja, M., Birke, A., 1993. Habitat use by adults of Ananstrepha obliqua (Diptera: Tephritidae) in a mixed mango and tropical plum orchard. Annals of the Entomological Society of America 86, 799-812.

Barker, R.J., 1977. Considerations in selecting sugars for feeding honey bees. American Bee Journal 117 (2), 76-77.

Bernstein, C., Jervis, M., 2008. Food-searching in parasitoids: the dilemma of choosing between 'immediate' or future fitness gains. In: Wajnberg, E., Bernstein, C., van Alphen, J.J.M. (Eds.), Behavioural Ecology of Parasitoids. Blackwell Publishing, Oxford, pp. 129-171.

De la Fuente, M., Penas, P.F., Sols, A., 1986. Mechanism of mannose toxicity. Biochemical and Biophysical Research Communications 140, 51-55.

Eijs, I., Ellers, J., Van Duinen, G.J., 1998. Feeding strategies in drosophilid parasitoids: the impact of natural food resources on energy reserves in females. Ecological Entomology 23, 133-138. 
Florida Department of Agriculture and Consumer Services, 1995. Division of Plant Industry. Bureau of Methods Development and Biological Control Caribbean Fruit Fly Mass Rearing Facility. Procedures Manual for Mass Rearing the Caribbean Fruit Fly Anastrepha suspensa (Lowe) (Diptera: Tephritidae) Gainesville, Florida.

Grohmann, K., Cameron, R.G., Buslig, B.S., 1995. Fractionation and pretreatment of orange peel by dilute acid hydrolysis. Bioresource Technology 54, 129-141.

Jervis, M., Kidd, N., 1999. Parasitoid adult nutritional ecology: implications for biological control. In: Hawkins, B., Cornell, H. (Eds.), Theoretical Approaches to Biological Control. Cambridge University Press, UK, pp. 131-151.

Jervis, M., Kidd, N., Heimpel, G., 1996. Parasitoid adult feeding behavior and biocontrol- a review. Biocontrol News and Information 17, 11-26.

Koptur, S., 1989. Extrafloral nectary-mediated interactions between insects and plants. In: Bernays, E.A. (Ed.), Insect-Plant Interactions. CRC Press, Florida, pp. 81-129.

López, M., Aluja, M., Sivinski, J., 1999. Hymenopterous larval-pupal and pupa parasitoids of Anastrepha flies (Diptera: Tephritidae) in Mexico. Biological Control 15, 119-129.

Montoya, P., Liedo, P., Bernay, B., Cancino, J., Barrera, J., Sivinski, J., Aluja, M., 2000 Biological control of Anastrepha spp. Diptera: Tephritidae) in mango orchards through augmentative releases of Diachasmimorpha longicaudata (Hymenoptera: Braconidae). Biological Control 8, 216-224

Morton, J., 1987. Fruits of Warm Climates. Media, Inc., Greensboro, N.C.

Muntean, E., 2010. Simultaneous carbohydrate chromatography and unsuppressed ion chromatography in detecting fruit juices adulteration. Chromatographia 71, S69-S74.

Ovruski, S., Aluja, M., Sivinski, J., Wharton, R., 2000. Hymenopteran parasitoids on fruit-infesting Tephritidae (Diptera) in Latin America and the southern United States: diversity, distribution, taxonomic status and their use in fruit fly biological control. Integrated Pest Management Reviews 5, 81-107.

Price, N.P.J., 2004. Acylic sugar derivatives for GC/MS analysis of 13C-enrichment during carbohydrate metabolism. Analytical Chemistry 76, 6566-6574.

Purcell, M.F., Jackson, C.G., Long, J.P., Batchelor, M.A., 1994. Influence of guava ripening on parasitism of the Oriental fruit fly, Bactrocera dorsalis (Hendel) (Diptera: Tephritidae), by Diachasmimorpha longicaudata (Ashmead)
(Hymenoptera: Braconidae) and other parasitoids. Biological Control 4, 396403.

Institute, S.A.S., 2002. User's Guide. SAS Institute, Cary, NC

Sivinski, J.M., Calkins, C.O., Baranowski, R., Harris, D., Brambila, J., Díaz, J., Burns, R.E., Holler, T., Dodson, G., 1996. Suppression of a Caribbean Fruit Fly (Anastrepha suspensa (Loew) Diptera: Tephritidae) population through augmented releases of the parasitoid Diachasmimorpha longicaudata (Ashmead) (Hymenoptera: Braconidae). Biological Control 6, 177-185.

Sivinski, J., Aluja, M., López, M., 1997. Spatial and temporal distributions of parasitoids of Mexican Anastrepha species (Diptera: Tephritidae) within the canopies of fruit trees. Annals of the Entomological Society of America 90, 604618.

Sivinski, J., Pinero, J., Aluja, M., 2000. The distributions of parasitoids (Hymenoptera) of Anastrepha fruit flies (Diptera: Tephritidae) along an altitudinal gradient in Veracruz, Mexico. Biological Control 18, 258-269.

Sivinski, J. Aluja, M. Holler, T, 2006. Food sources for adult Diachasmimorpha longicaudata, a parasitoid of tephritid flies: effects on longevity and fecundity. Entomologia Expirimentalis et Applicata 118, 193-202.

Villamiel, M., Martinez-Castro, I., Olano, A. Corzo, N., 1998. Quantitative determination of carbohydrates in orange juice by gas chromatography. Zeitschrift für Lebensmitteluntersuchung und -Forschung 206, 48-51.

Wäckers, F., 1999. Gustatory response by the hymenopteran parasitoid Cotesia glomerata to a range of nectar and honeydew sugars. Journal of Chemical Ecology 25, 2863-2877.

Wäckers, F., 2001. A comparison of nectar- and honeydew sugars with respect to their utilization by the hymenopteran parasitoid Cotesia glomerata. Journal of Insect Physiology 47, 1077-1084.

Wharton, R., Marsh, P., 1978. New World Opiinae (Hymenoptera: Braconidae) parasitic on Tephritidae (Diptera). Journal of the Washington Academy of Science 68, 147-167.

Wong, T., Ramadan, M., 1993. Mass-rearing biology of larval parasitoids (Hymenoptera: Braconidae: Opiinae) of tephritid fruit flies in Hawaii. In: Anderson, T., Leppla, N. (Eds.), Advances in Insect Rearing for Research and Pest Management. Westview, CO, pp. 405-426.

Zar, J., 1974. Biostatistical Analysis. Prentice-Hall, Englewood Cliffs, NJ. 